\title{
TRANÇANDO IDENTIFICAÇÕES: A POÉTICA DE CONCEIÇÃO EVARISTO ENTRE OS MOVIMENTOS NEGRO E FEMINISTA
}

Tatiana Sena

\begin{abstract}
RESUMO: Este artigo analisa como a escritora Conceição Evaristo articula, em sua produção poética e crítica, as identificações oriundas de sua militância nos movimentos negro e feminista, a fim de visibilizar o protagonismo das mulheres negras na formação do país. Elegendo como ponto de vista dissidente o local social do sujeito feminino negro, a autora opera uma releitura crítica da memória da escravidão, explicitando as estratégias de resistência das mulheres negras à história de objetivação e subalternização imposta pelo escravismo colonial.
\end{abstract}

PALAVRAS-CHAVE: Conceição Evaristo. Movimento negro. Feminismo. Resistência.

\begin{abstract}
This article examines how the writer Conceição Evaristo articulates in her poetry and criticism, the identifications coming from her activism in the black and feminist movements in order to visualize the role of black women in shaping the country. From the social location of black women as a dissenting point of view, the author operates a critical rereading of the memory of slavery, explaining the strategies of resistance of black women to the history of objectification and subordination imposed by colonial slavery.
\end{abstract}

KEYWORDS: Conceição Evaristo. Black movement. Feminism. Resistance.

\section{INTRODUÇÃO: MULHERES NEGRAS - RECONSTRUINDO ARQUIVOS E MEMÓRIAS}

A possibilidade de representar a sua diferença se constitui como um catalisador para a subjetivação individual e coletiva. As populações negras, durante séculos, tiveram suas vozes silenciadas pelo aparato coercitivo dos dispositivos de dominação sócio-cultural no Brasil. As/Os afrodescendentes resistiram aos cerceamentos impostos a sua fala, desde o período colonial e, numa trajetória plurissecular, foram construindo locais de enunciação que transgridem e questionam o padrão ocidental. A escrita literária tem sido um espaço privilegiado para entendermos esses embates culturais na contemporaneidade, visto que sua apropriação por escritoras e escritores negros tem instaurado novas perspectivas estéticas, orientando para a emergência de outras epistemologias. 
Neste artigo, analiso as interfaces entre as identificações étnica e de gênero na produção poética e crítica da escritora mineira Conceição Evaristo, evidenciando como a autora alinhase a outras vozes femininas negras que procura(ra)m refletir sobre o saber gerado a partir da experiência da mulher negra na contemporaneidade. A perspectiva crítica de Conceição Evaristo utiliza a escrita literária como um local de enunciação transgressivo, que pode reativar e reconfigurar os arquivos da memória da escravidão no Brasil, denunciando assim as consequências da dominação colonial imposta à população negra, em especial ao sujeito feminino negro.

Conceição Evaristo (2004) considera que "a palavra poética é um modo de narração do mundo". Há uma propensão para narrar nos seres humanos, um desejo de engendrar narrações. Estas acabam por estear a constituição de subjetividades. A resistência cultural negra impediu a invisibilização do caráter contestador das culturas afro-diaspóricas, possibilitando a emergência de outras sensibilidades, que foram recalcadas, através de outros locais de enunciação cultural, a fim de denunciar as consequências da modernidade ocidental.

Esses outros locais de fala, que dialogam e deslocam o eixo hegemônico, opõem-se a fixidez e a sedimentação. Contrapondo-se às fronteiras nacionalizantes do pensamento, as produções culturais dos afro-diaspóricos apresentam-se como um campo fértil e vigoroso do pensamento estético, intelectual e acadêmico da contemporaneidade. Abriram, inclusive, outras perspectivas criativas e críticas para a modernidade cultural do Ocidente. Afinal, não podemos perder de vista os intercâmbios e conexões entre o hegemônico e o periférico. Se, como postulou Edward Said (1995, p. 38), existe uma luta pela hegemonia geopolítica, "abrangendo também ideias, formas, imagens e representações", o Atlântico negro coloca em xeque a categoria de nação.

Dessa forma, gostaríamos de acentuar a necessidade da recomposição dos arquivos das experiências negras na diáspora e na África, a fim de que possamos como salientou Paul Gilroy, em palestra realizada em Salvador ${ }^{1}$, fazer com que a história do colonialismo seja parte da história moral do planeta. Ao fazer isso, a história dos africanos e dos afrodiaspóricos também comporá a história moral da humanidade.

A escritora afro-americana Toni Morrison também enfatizou a necessidade do resgate dos arquivos das experiências negras para compreender a modernidade, assim como para

\footnotetext{
${ }^{1}$ No dia 04 de agosto de 2006, no Teatro Gregório de Matos, durante as atividades da Fábrica de Ideias 2006.
} 
possibilitar a emergência das respostas negras aos impasses gerados pelo modus vivendi moderno. Para Morrison,

[...] a vida moderna começa com a escravidão... Do ponto de vista das mulheres, em termos de enfrentar os problemas que o mundo enfrenta agora, as mulheres negras tiveram de lidar com problemas pós-modernos no século XIX e antes. Essas coisas tiveram de ser abordadas pelo povo negro muito tempo antes: certos tipos de dissolução, a perda e a necessidade de construir certos tipos de estabilidade. Certos tipos de loucura, enlouquecer deliberadamente (...). Essas estratégias de sobrevivência constituíam a pessoa verdadeiramente moderna. São uma resposta aos fenômenos ocidentais predatórios. Você pode chamar isto de ideologia e de economia, mas trata-se de uma patologia. A escravidão dividiu o mundo ao meio, ela o dividiu em todos os sentidos. Ela dividiu a Europa. Ela fez deles alguma outra coisa, ela fez deles senhores de escravos, ela os enlouqueceu. Não se pode fazer isso durante centenas de anos sem que isto cobre algum tributo. Eles tiveram de desumanizar não só os escravos, mas a si mesmos. Eles tiveram de reconstruir tudo a fim de fazer este sistema parecer verdadeiro. Isto tornou tudo possível na Segunda Guerra Mundial. Tornou necessária a Primeira Guerra Mundial. Racismo é a palavra que empregamos para abarcar tudo isto (MORRISON apud GILROY, 2001, p. 412-413)

A disputa pela memória do passado possibilita a reelaboração e redirecionamento da história do presente. Em sua produção poética, Evaristo enfatizou a necessidade de exorcizar os terrores da brutalidade excessiva imposta ao sujeito negro no geral e, mais especificamente, às mulheres negras, tendo em vista o apagamento de seu protagonismo na história do país.

Essa reivindicação vem justamente porque nós estamos fazendo questão de estar em todos os espaços, nas universidades, na vida pública, nos meios de comunicação. Por isso acredito que hoje há uma afirmação que reivindica. Mas eu também acho que a gente não deve esquecer o passado, pois ainda precisamos exorcizar essa nossa dor. Creio que não esquecer impulsiona você a cobrar, porque nada que a sociedade está nos oferecendo é de graça. Então vale relembrar o passado. (EVARISTO, 2006)

O relembrar seria uma forma de revisão historiográfica e reparação moral contra as implicações raciológicas. É necessário enraizar historicamente os discursos racistas, vinculando-os ao "encaixe histórico, político e cultural" nos quais foram formatados (HALL, 2006), para explicitar as estratégias históricas de resistência e contestação que emergiram nesses contextos.

A participação das mulheres na resistência e reconstrução cultural dos arquivos das experiências negras foi fundamental para a preservação dos saberes africanos. O papel da 
matriarca negra, por exemplo, reagrupou a desagregação imposta aos povos africanos na diáspora. A organização nuclear da família negra, em torno da figura materna, pode ser mapeada tanto nos terreiros de candomblé como na maioria das famílias de Salvador, por exemplo, nas quais a chefe de família é uma mulher negra. Vale ressaltar que essas famílias chefiadas por mulheres negras apresentam os piores índices sócio-econômicos dentre todos os outros arranjos familiares. Essa situação só pode ser entendida à luz do contexto histórico em que foi configurada a exploração das mulheres negras. Por isso, reconstruir os arquivos das experiências negras é uma tarefa de vida na poesia de Conceição Evaristo.

\title{
1. CONCEIÇÃO EVARISTO: UMA VIDA RODEADA DE PALAVRAS
}

Maria da Conceição Evaristo de Brito nasceu em Belo Horizonte, em 1946. No início da década de 1970, muda-se para o Rio de Janeiro. Nessa cidade, Conceição Evaristo acompanhou de perto as movimentações político-culturais das minorias políticas, sobretudo dos movimentos negro e feminista. A escritora se mudara para o Rio de Janeiro, em decorrência das dificuldades encontradas para transpor as barreiras sociais, marcadamente racistas, da sociedade mineira, como a própria autora destacou:

\begin{abstract}
Enquanto trabalhava como doméstica e após concluir o Curso Normal, eu sonhava em dar aula em Belo Horizonte. Mas aí entra uma questão seríssima. Em 1971, não havia concurso para o magistério e, para ser contratada como professora era necessário apadrinhamento. E as famílias tradicionais para quem nós trabalhávamos não me indicariam e nunca indicaram; não imaginavam e não queriam para mim um outro lugar a não ser aquele que "naturalmente" haviam me reservado. Houve mesmo uma patroa de minha tia, numa casa em que eu ainda menina e já mocinha ia fazer limpeza, lavar fraldas de bebês, ajudar nas festas, entregar roupas limpas e buscar as sujas, que fez a seguinte observação: "Maria, não sei porquê você esforça tanto para a Preta estudar!". (EVARISTO apud DUARTE, 2006)
\end{abstract}

Conceição Evaristo, com apoio da mãe, persistiu nos estudos e tornou-se professora. Em entrevista concedida ao jornal Estado de Minas, a autora reconstituiu sua trajetória de vida, assinalando a importância da literatura em sua vida. A condição social de escritora é índice biográfico relevante em seu percurso de vida, mas simboliza também a trajetória de 
resistência de toda a comunidade feminina negra, para ampliar o leque dos locais sociais das mulheres negras.

Começando minha história pelo lado feliz, digo que voltar a Belo Horizonte como escritora, com um livro indicado pela UFMG, consagra uma vida vitoriosa. Nasci e fui criada na cidade, em situação de extrema pobreza, numa favela no Bairro Cruzeiro. Em 1971, ainda morava na favela, que foi desapropriada, nos causando muita dor. Atravessei o chão da cidade com trouxa de roupa na cabeça para trabalhar na casa das patroas, ajudando minha mãe a catar papel para completar a renda. No entanto, a cidade me deu régua e compasso, e eu saí traçando meus caminhos. Tive muito apoio da família, especialmente da minha mãe e tia, para mudar o destino que as pessoas queriam que ficasse estabelecido para mim. (EVARISTO, 2007)

A escrita literária foi o local onde a poeta Conceição Evaristo encontrou refúgio. E é como uma refugiada que Evaristo vai conduzir sua escritura. A autora confidenciou: "sempre encontrei na escrita uma maneira de suportar o mundo. Era o que me permitia viver, questionar, buscar respostas" (EVARISTO, 2007). A escrita literária será o lar possível para Conceição Evaristo em face das alienações impostas ao sujeito feminino negro na sociedade brasileira. No poema De mãe, marcado por fortes traços biográficos, Conceição Evaristo vincula sua expressividade ao legado matrilinear da ancestralidade negra, enfatizando a importância de sua mãe na formação de sua voz poética.

O cuidado de minha poesia

Aprendi foi de mãe

mulher de pôr reparo nas coisas

e de assuntar a vida.

A brandura de minha fala

na violência de meus ditos

ganhei de mãe

mulher prenhe de dizeres

fecundados na boca do mundo.

$$
\text { (...) }
$$

Foi de mãe esse meio riso

dado para esconder

alegria inteira

e essa fé desconfiada,

pois, quando se anda descalço

cada dedo olha a estrada.

$$
\text { (...) }
$$

e me ensinou,

insisto, foi ela 


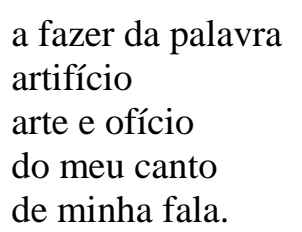

(EVARISTO, 2002, p. 36)

O cuidado na poética de Evaristo exprime-se pelo lirismo com que a poeta serenamente tece a trama polirrítmica de sua fala, num tom confidente de quem rememora. A oralidade no poema ressalta o uso das expressões populares, cujas construções são estigmatizadas pelas prescrições da gramática normativa. A sintaxe da língua falada confere ao termo "mãe" o foco da oração com o uso da expressão "foi de mãe", visto que o termo expletivo "foi de" quebra a regência do verbo "aprender". Conceição Evaristo transgride a sintaxe da escrita, a fim de destacar sintática e semanticamente a figura materna. Essa subversão linguística demarca a opção do sujeito enunciador pela sintaxe das normas populares.

A presença da oralidade da fala poética transparece também pela presença de termos coloquiais como "pôr reparo" e "assuntar". Essas opções discursivas são uma atitude política extremamente contestadora. A brandura de uma musicalidade negra ao falar impregna o poema que se tensiona com conteúdo violento dos enunciados do sujeito poético, denunciando as alegrias censuradas das mulheres negras, o "meio sorriso" de quem desconfia da felicidade e da própria fé.

Os árduos esforços diários das mulheres negras, ainda hoje, para garantir uma vida mais digna, são trilhados a partir dessa consciência da ausência, da deriva contínua, da consciência de que "quando se anda descalço, cada dedo olha a estrada". Entretanto, contrapondo-se às subjugações difundidas pelo racismo, as mulheres negras formam um elo matrilinear de resistência cultural. A aprendizagem emerge da experiência, do fazer poético como expressão política no cotidiano, urdido engenhosamente nas brechas dos mecanismos de silenciamento às vozes divergentes das mulheres negras.

Arte e ofício possibilitam a reconstrução de uma genealogia crítica, intelectual e moral, a qual se contrapõe a cisão entre estética e ética. Para o teórico afro-diaspórico Paul Gilroy (2001, p. 100), “a literatura autobiográfica e as maneiras criativas especiais e exclusivas de manipular a linguagem falada (...) transbordaram os vasilhames que o estado-nação moderno forneceu" aos afrodescendentes na diáspora. 
A luta para a legitimação do local de fala das autoras e autores negros se confunde com as falas dos sujeitos enunciadores criados no âmbito da literatura negra no Brasil. Para a escritora Conceição Evaristo, "há uma relação muito grande entre o sujeito autoral com a ficção na literatura afro-brasileira" (EVARISTO, 2007). A biografia de Conceição Evaristo é marcada pelos entraves recorrentes às mulheres negras, em nossa sociedade, os quais ainda delimitam os devires do sujeito feminino negro, restringindo-lhes as possibilidades de ocuparem outros lugares do que os previamente estabelecidos.

\section{ESCRITORAS NEGRAS E LITERATURA AFRO-BRASILEIRA}

No dia 13 de julho de 2006, presenciei a palestra da escritora Conceição Evaristo, durante a II Conferência de Intelectuais da África e da Diáspora (II CIAD), realizada em Salvador, entre os dias 11 a 16 de julho de 2006. A autora participava da mesa de debate Literatura, arte e renascimento africano, que englobava as discussões do grupo temático As humanidades como pontes de diálogo entre a África e a Diáspora. Na ocasião, Conceição Evaristo confidenciou ao público: "tenho medo de não dar conta da minha fala". Essa preocupação é compreensível, especialmente quando percebemos que a fala da autora representava não apenas sua voz, mas uma fala tramada coletivamente no âmbito da literatura afro-brasileira como um todo, e, mais especificamente, das escritoras negras do Brasil. No contexto das escritoras negras afro-brasileiras, no qual Conceição Evaristo está inserida, podemos destacar as figuras de Geni Guimarães, Miriam Alves, Celinha, Esmeralda Ribeiro, Lia Vieira, Sônia Fátima, Ana Beatriz Gonçalves, entre outras. Este momento significativo visibiliza a trajetória de contestação ao cânone nacional por parte dessa produção literária divergente.

A escrita literária que tem sido produzida por escritoras e por escritores autodeclarados afrodescendentes é multifacetada, em seus mais diversos campos de atuação. Até mesmo na escrita acadêmica de autoras e autores negros, o relato e o testemunho entrecortam o texto, como forma de entrelaçar o diálogo com o mundo acadêmico e com grupos sociais marginalizados. Essa estratégia discursiva, marcadamente híbrida, evidencia a fragmentação da representatividade política, que desmistifica a verticalidade do poder de fala das/dos 
intelectuais tradicionais na contemporaneidade. A exemplo disso, podemos citar as produções de Conceição Evaristo, Lélia Gonzales, Luiza Bairros, bell hooks, entre outras.

As escritoras e escritores negros trabalham utilizando a norma vernácula para transgredirem a estandartização da norma culta, aproveitando-se da transgressividade linguística precípua das normas populares, nas quais o conceito de "erro" é solapado pelo devir da própria língua. Lélia Gonzales acentuou o papel da mulher negra, através das mães pretas, na formatação das normas vernáculas no Brasil:

Conscientemente ou não, ela passou para o brasileiro branco as categorias das culturas negro-africanas de que era representante. Foi por aí que ela africanizou o português falado no Brasil (transformando-o em "pretuguês") e, consequentemente, a cultura brasileira. (GONZALES apud BAIRROS, 2007).

A população negra foi excluída politicamente e seus quadros de referências sócioculturais de matrizes africanas foram marginalizados. O local da exclusão é formado pelos sobejos do despotismo totalizante que a todos querem conformar numa homogeneidade fictícia chamada nação. O excluído é o excesso do discurso identitário nacional. A fatalidade de Conceição Evaristo é, justamente, esse excesso transgressivo. A partir deste, a poeta se (re)compõe como um sujeito em deriva, pois tenta reconstituir sua identidade com base em fragmentos de memória pessoais e coletivos.

Através da densa trama rítmica que tece em sua escritura, Conceição Evaristo evoca e convoca as sensibilidades das mulheres negras marginalizadas. Dessa sensibilidade da diferença, emergem as contestações das fronteiras rígidas, visto que rompem categorias estanques do pensamento ocidental. Dessa forma, emerge uma consciência que opera em contraponto, na qual a composição polifônica e híbrida desarticula a força homogeneizante que visa excluir as vozes dissidentes. A população negra construiu diversos locais de enunciação alternativos, nos quais contesta veementemente a exclusão imposta pelas estruturas racistas. Essa ânsia por falar pode ser resumida na provocação de Lélia Gonzales:

na medida em nós negros estamos na lata de lixo da sociedade brasileira, pois assim o determina a lógica da dominação ...o risco que assumimos aqui é o do ato de falar com todas as implicações. Exatamente porque temos sido falados, infantilizados... que neste trabalho assumimos nossa própria fala. Ou seja, o lixo vai falar, e numa boa. (GONZALES apud BAIRROS, 2007) 
A literatura afro-brasileira tem sido um dos principais espaços para o resgate das memórias negras. Os textos dessa produção literária apresentam um tecido mesclado, no qual a presença da oralidade possibilita novas vertentes para a construção de sentido, vinculandose aos saberes ancestrais africanos, nos quais a oralidade é modo privilegiado na transmissão de saberes (SOUZA, 2005; FONSECA, 2006). Do ponto de vista cultural e literário, a literatura afro-brasileira ressignificou o legado histórico colonial, demonstrando o que uma literatura menor pode fazer em um língua maior. Para os teóricos Giles Deleuze e Félix Guattari, uma literatura menor seria aquela cujo caráter transgressor deslocaria os padrões da literatura estabelecida. A força revolucionária da literatura menor seria decorrente da desterritorialização da língua, da ramificação do individual no imediato-político e do agenciamento coletivo de enunciação (DELEUZE, GUATTARI, 1977, p. 28).

A literatura afro-brasileira desconstrói as fronteiras entre contestação individual e coletiva. Cada enunciação se conecta a outras enunciações, cujos valores posicionais se determinam mutuamente, fazendo com que cada sentença adquira uma urgência de vida e de morte. As temáticas dessa vertente literária se disseminam por eixos que abrangem questões identitárias acerca das corporalidades, oralidades e memórias negras e que explicitam a atuação social da poesia. Denunciam enfaticamente as alienações impostas aos sujeitos negros, com base em discursos racistas, difundidos desde o período colonial, e que encontram permanências remodeladas na contemporaneidade. Os poemas criticam ética e esteticamente as restrições às subjetividades negras.

A adoção do romance Ponciá Vicêncio, de Conceição Evaristo, pela Universidade Federal de Minas Gerais para o vestibular 2008 e do livro Cadernos Negros: Os melhores poemas, para o vestibular 2008 da Universidade Federal da Bahia, representa um marco na história da literatura afro-brasileira. A história de literatura afro-brasileira pode ser compreendida a partir de marcos predecessores, que remontam ao século XIX, como é o caso de Luis Gama, Cruz e Souza e da primeira romancista brasileira, Maria Firmina dos Reis. Neste aspecto, a pesquisadora Sueli Carneiro ressaltou que

O esforço pela afirmação de identidade e de reconhecimento social representou para o conjunto das mulheres negras, destituído de capital social, uma luta histórica que possibilitou que as ações dessas mulheres do passado e do presente (especialmente as primeiras) pudessem ecoar de tal forma a ultrapassarem as barreiras da exclusão. O que possibilitou, por exemplo, que a primeira romancista brasileira fosse uma negra a despeito das contingências sociais em que ela emergiu? (CARNEIRO, 2003) 
A articulação literária afro-brasileira destacou-se durante a efervescência transnacional nos âmbitos político e cultural dos movimentos negros da década de 1970, contribuindo para a criação de movimentos e entidades que organizaram as ações contra o racismo no país. O ano de 1978 se iniciou com a Escola de Samba Quilombo, do Rio de Janeiro, abordando os noventa anos da abolição em seu enredo, escrito por Antônio Candeia Filho, com base nos textos de Lélia Gonzales e de outros estudiosos negros. Em junho desse mesmo ano, o Movimento Negro Unificado (MNU) é fundado, com colaboração ativa da cientista social Lélia Gonzales, que considera que a fundação do MNU “consistiu no mais importante salto qualitativo nas lutas da comunidade negra brasileira, na década de setenta" (GONZALES apud BAIRROS, 2007).

Em 1978, também é criado o Festival Comunitário Negro Zumbi (FECONEZU), que congregava afrodescendentes interessados em visibilizar a herança cultural negra na sociedade brasileira. Durante esse Festival, foi lançado o primeiro volume da série $O s$ Cadernos Negros. A autora Conceição Evaristo ressaltou, em um de seus artigos publicados na internet, como esse momento de intensa movimentação negra, e de intensificação cultural, ajudou a dinamizar a produção literária negra, na década de 70:

O discurso literário negro-brasileiro não está desvencilhado das pontuações ideológicas do Movimento Negro. E, embora, durante quase todo o processo de formação da literatura brasileira existissem vozes negras desejosas em falar por si e de si, a expressividade negra vai ganhar uma nova consciência política sob inspiração do Movimento Negro, que volta para a reafricanização, na década de 70. O Movimento de Negritude, no Brasil, tardiamente chegado, vem misturado aos discursos de Lumumba, Black Panther, Luther King, Malcolm X, Angela Davis e das Guerras de Independência das colônias portuguesas. Esse discurso é orientado por uma postura ideológica que levará a uma produção literária marcada por uma fala enfática, denunciadora da condição do negro no Brasil, mas igualmente valorativa, afirmativa do mundo e das coisas negras. (EVARISTO, 2004)

Essa análise se coaduna com as reflexões do teórico afro-diaspórico Stuart Hall. Ele considera que os repertórios da cultura negra sofreram uma dupla sobredeterminação, decorrentes da pressão exercida pelas heranças culturais africanas e das releituras críticas desse patrimônio cultural pelas "condições diaspóricas nas quais as conexões foram forjadas" (2006, p. 324). Processos de apropriação, cooptação e rearticulação entre referências culturais ocidentais e africanas "conduziram a inovações linguísticas na estilização retórica do corpo, a 
formas de ocupar um espaço social alheio, a expressões potencializadas, a estilos de cabelo, a posturas, gingados e maneiras de falar, bem como os meios de constituir e sustentar o companheirismo e a comunidade" (2006, p. 324-325). Esse contexto sócio-histórico da diáspora evidencia a hibridez cultural da literatura afro-brasileira.

Essas intensas movimentações se tornam mais visíveis para a crítica hegemônica somente a partir de 1979, como destacou o crítico Silviano Santiago (1998) no ensaio em que analisa o impacto que a distensão política promoveu nos campos artístico e cultural brasileiros, rumo à democratização nacional. Santiago caracteriza os anos de 1979 a 1981 como o início do "fim" do século XX no Brasil e na América Latina, de modo mais geral. Silviano Santiago evidencia a extemporaneidade na fala de Lélia Gonzales, em entrevista concedida à Heloísa Buarque de Hollanda. Através dos depoimentos de Gonzales, podemos perceber algumas contestações que passariam a compor a plataforma política dos afrodescendentes nos anos posteriores, como a denúncia contra a assimilação pedagógica e política do negro, requisitando assim autonomia cultural para que, a partir desta, as negociações políticas possam acontecer entre os grupos étnicos.

\section{MULHERES NEGRAS: "NOSSOS FEMINISMOS"}

$\mathrm{Na}$ maioria das suas produções criativas, Conceição Evaristo reconstrói o local de subalternidade ocupado pelas mulheres negras. O ponto de vista da narração poética se expressa a partir da visão de mulheres negras, que muitas vezes ocupam funções subalternas na sociedade, como o ponto de vista da empregada doméstica, por exemplo. Retornando às suas próprias memórias e às memórias das mulheres de sua própria história familiar, Evaristo revisa o sistema de opressão e subordinação desse segmento profissional pelas famílias burguesas na modernidade. A partir da perspectiva dissidente da empregada doméstica, a poeta desconstrói a lógica do racismo moderno, que ainda impede às negras e aos negros de serem percebidos como agentes cognitivos, com história intelectual. A perspectiva intelectual da empregada doméstica pode ser enquadrada na categoria do estranho interno (outsider within) da pesquisadora afro-americana Patrícia Hill Collins (2000; 2005; 2009). 
Quando Evaristo convoca as vozes silenciadas dessas mulheres, resgata do esquecimento das narrativas tradicionais a memória transgressiva de suas perspectivas intelectuais subjugadas, as quais foram transmitidas através de gerações de vozes femininas sufocadas. No poema "Vozes-mulheres, a poeta Conceição Evaristo evidencia a permanência perversa da dominação racista sobre as possibilidades sociais das mulheres negras. A força de trabalho do sujeito feminino negro é explorada por gerações de "brancos donos de tudo". A voz abafada debaixo das "roupagens sujas dos brancos" emerge para denunciar a sordidez dos privilégios sociais, marcadamente racistas, através dos quais os "brancos" se locupletam. A luta plurissecular contra o racismo se inscreve na voz poética do sujeito feminino, que reverbera, ainda perplexa:

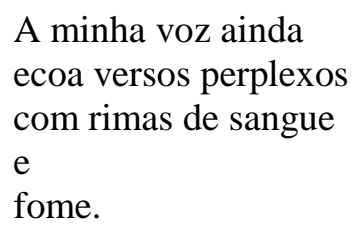

A voz de minha filha recorre todas as nossas vozes recolhe em si as vozes mudas caladas engasgadas nas gargantas.
A voz de minha filha recolhe em si a fala e o ato. O ontem - o hoje - o agora. $\mathrm{Na}$ voz de minha filha se fará ouvir a ressonância o eco da vida-liberdade.

(EVARISTO, 1990, p. 32)

Conceição Evaristo faz o verso ecoar vibrante com a sonoridade das consoantes implosivas na palavra "perplexo", evocando a musicalidade das marcações dos tambores africanos. Os tambores de Minas em Evaristo anunciam uma mudança, uma libertação que vem marcada pelo sangue e pela fome de séculos de violência e privação material. O sujeito enunciador projeta, a partir do momento oscilante do hoje, o vir-a-ser no qual a filha recolhe todas as vozes femininas passadas e as atualiza, tornando presente essas memórias. A ressonância só é possível pelo ato reiterado, pelo eco contínuo das vozes mulheres ao longo 
da trajetória política das mulheres negras. O resgate histórico pela rememoração desloca a história oficial, fissurando a narrativa do Ocidente.

As mulheres negras para Evaristo são as guardiãs das memórias negras. No poema $A$ noite não adormece nos olhos das mulheres, a poeta assinala a "vigília atenta", na qual "há mais olhos que sono". Através dos olhos das mulheres, "meninas luas", a autora potencializa o ponto de vista dissidente contra os terrores impostos pela modernidade ocidental racista. As "lágrimas suspensas" são como vírgulas silenciosas, pontuando os "lapsos" da história ocidental e das histórias pessoais, afinal "nossas molhadas lembranças" são tão traumáticas que, por vezes, submergem completamente nas profundezas de uma subjetivação esfacelada. Em vista da permanência da brutalidade excessiva do racismo, a poeta acentua a tarefa contínua da vigília:
A noite não adormecerá jamais nos olhos das fêmeas pois do nosso sangue-mulher do nosso líquido lembradiço em cada gota que jorra um fio invisível e tônico pacientemente cose a rede de nossa milenar resistência. (EVARISTO, 1996, p. 26)

As mulheres negras tiveram um protagonismo fundamental na construção dos movimentos negros e movimentos sociais, como as associações de moradores de bairros periféricos. Entretanto, o papel das mulheres negras foi minimizado dentro do movimento feminista ocidental hegemônico, assim como dentro do próprio movimento negro. Aos companheiros militantes, a poeta Conceição Evaristo deixa um recado no poema Malungo, brother, irmão:

\author{
No fundo do calumbé \\ nossas mãos sempre e sempre \\ espalmam nossas outras mãos \\ moldando fortalezas esperanças, \\ heranças nossas divididas com você: \\ Malungo, brother, irmão. \\ (EVARISTO, 1996, p. 24)
}


Para Conceição Evaristo, "o nosso feminismo [negro] vem para a gente se afirmar como pessoa" (EVARISTO, 2006), em contraposição às feministas brancas que precisaram se afirmar contra a tutela machista que as impedia de trabalharem, por exemplo. As mulheres negras sempre tiveram que trabalhar. Em vista disso, a afirmação feminina negra era contra a dominação imposta pelas patroas, nas casas de famílias burguesas. A cientista social Lélia Gonzales diagnosticou as ambiguidades da "universalização" do movimento feminista:

se as transformações da sociedade brasileira nos últimos vinte anos favoreceram "a mulher", não podemos deixar de ressaltar que essa forma de universalização abstrata encobre a realidade vivida, e duramente, pela grande excluída da modernização conservadora imposta pelos donos do poder do Brasil pós-64: a mulher negra. É por aí que se entende, por exemplo, uma das contradições do movimento de mulheres no Brasil. (GONZALES, 1994)

No artigo "Nossos feminismos revisitados", a socióloga Luiza Bairros (2000) traça as divergências do feminismo negro em relação ao feminismo hegemônico, vinculado à epistemologia ocidental. Evidenciam-se, dessa forma, diferenças do projeto político do feminismo hegemônico e do feminismo negro. A teoria do ponto de vista, proposta pela teórica afro-americana Patrícia Hill Collins (2000; 2005; 2009), privilegia o pensamento oriundo da experiência das mulheres negras, exprimindo uma consciência sobre a articulação de raça e classe social na estruturação do gênero. A partir da marginalidade peculiar que ocupam, as mulheres negras constroem suas contribuições intelectuais e expressam seus pontos de vista, questionando as ações e ideologias dos grupos hegemônicos. A teórica afroamericana bell hooks considera que o ponto de vista da mulher negra deve prevalecer nas práticas cotidianas, exprimindo uma resistência imanente da política negra.

Como nas lutas organizadas que aconteceram nos anos 1960 e princípios da década de 1970, nós, as mulheres negras, como indivíduos, devemos lutar sozinhas por adquirir a consciência crítica que nos capacite para examinar as questões de raça e beleza e pautar nossas escolhas pessoais de um ponto de vista político (HOOKS, 2005).

A "vigília atenta" permanece nas lutas contemporâneas por melhores condições de vida para as negras e os negros no Brasil. As conquistas obtidas demonstram que a "resistência milenar" das mulheres que não dormem está surtindo efeitos. A escritora Conceição Evaristo tem participado ativamente dessa rede de mulheres que vigiam e tecem as tramas de um futuro mais digno. Evaristo participa da organização não-governamental Criola, fundada por 
Mãe Biata de Iyemonjá, que instrumentaliza jovens negras para o combate ao racismo e ao sexismo. Em 2007, por seu trabalho, Mãe Biata de Iyemonjá recebeu o prêmio Bertha Lutz no Senado Federal. Entretanto, os cerceamentos ao ser feminino negro foram tão amplos que uma reversão eficaz deve se pautar em várias esferas da existência feminina negra. Como ressaltou Alzira Rufino:

Embora esteja em germinação um tempo de cidadania negra, para a grande maioria das mulheres negras, a violência passa pela enxurrada de nãos. Ainda hoje negam-nos qualquer vida psicológica e intelectual, exibem nosso corpo colonizado pelas fantasias sexuais mais secretas - um corpo sem raízes na história e sem afetividade. (RUFINO, s.d.)

Conceição Evaristo, assim como Alzira Rufino, reconstrói os arquivos de memórias das mulheres negras, ressaltando o corpo político e afetivo das mulheres negras em suas produções poéticas. Assumindo a dupla identificação, étnica e de gênero, Evaristo desfaz os fios coercitivos e refaz as linhas de sua trajetória, a fim de se integrar a uma linhagem crítica em prol da cidadania das mulheres negras.

\section{CONSIDERAÇÕES FINAIS}

Como Hall assinalou acerca da cultura popular, a literatura também não traz "a verdade da nossa existência" (2006, p. 329), antes propõe uma "arena profundamente mítica", na qual as/os afrodescendentes descobrem como são representadas/os, bem como se representam a si próprias/os a partir desses repertórios culturais. Dessa forma, A escritora Conceição Evaristo representa a mulher negra, privilegiando o ponto de vista dessa mulher, a fim de problematizar as representações estereotipadas das mulheres negras na cultura brasileira. Evaristo recria e recompõe imagens, descortinando múltiplas possibilidades de subjetivações para as mulheres negras, através de uma poesia que sonha um novo mundo:

E os sonhos, submersos e disformes avolumaram-se engrandecidos anelando-se uns aos outros pulsaram como sangue-raiz nas veias ressecadas de um novo mundo. (EVARISTO, 1990, p. 31) 
A construção do novo mundo não se desvincula da construção de um outro paradigma social, no qual surjam "novos modos de amizade, felicidade e solidariedade consequentes com a superação da opressão racial sobre a qual se assenta a modernidade e sua antinomia do progresso racional, ocidental, como brutalidade excessiva" (GILROY, 2001, p. 97). A contracultura do Atlântico negro tem sido tecida cotidianamente na prática de uma outra mundividência. A voz da escritora Conceição Evaristo, articulada às vozes de outras autoras negras, neste ensaio, evidenciam que a participação das mulheres negras tem sido fundamental na construção desse novo mundo, através de posturas éticas que buscam entrelaçar as perspectivas provenientes das identificações étnicas e de gênero. Através de suas reflexões, as mulheres negras vêm construindo respostas aos impasses gerados pela modernidade ocidental, construindo novas possibilidades de vida, não apenas para si, mas para toda humanidade.

\section{REFERÊNCIAS:}

BAIRROS, Luiza. Lembrando Lélia Gonzales, 2007. Disponível em: http://www.casadeculturadamulhernegra.org.br/quem_somos_frameset.htm - Acesso em: 14 de jun. 2007.

BAIRROS, Luiza. Nuestros Feminismos revisitados. In: Política y Cultura. 2000. Disponível em: http://redalyc.uaemex.mx/redalyc/pdf/267/26701408.pdf - Acesso em: 17 jun. 2007.

CARNEIRO, Sueli. Mulheres em movimento. In: Estud. av. vol.17 n ${ }^{\circ} 49$ São Paulo Sept./Dec. $2003 . \quad$ Disponível http://www.scielo.br/scielo.php?script=sci_arttext\&pid=S0103-40142003000300008 em: Acesso em: 14 jun. 2007.

COLLINS, Patricia Hill. Black feminist thought: knowledge, consciousness, and the politics of empo. Routledge-USA, 2000.

COLLINS, Patricia Hill. Black sexual politics: african americans, gender, and the new racism (pb). Routledge-USA, 2005.

COLLINS, Patricia Hill; ANDERSEN, margaret 1., Race, class, \& gender: an anthology.Cengage Learning int, 2009. 
DELEUZE, Gilles; GUATTARI, Félix. O que é uma literatura menor? In: Kafka: por uma literatura menor. Rio de Janeiro: Imago, 1977.

DUARTE, Eduardo de Assis. O Bildungsroman afro-brasileiro de Conceição Evaristo. In: Rev. Estud. Fem. vol.14 n ${ }^{\circ} 1$ Florianópolis Jan./Apr. $2006 . \quad$ Disponível em: http://www.scielo.br/scielo.php?pid=S0104-026X2006000100017\&script=sci_arttext Acesso em: 14 jun. 2007.

EVARISTO, Conceição. Literatura negra: uma voz quilombola na literatura brasileira. 2004. Disponível: bibliotecavirtual.clacso.org.ar/ar/libros/aladaa/evaris.rtf. Acesso: 05 abr. 2012. 2006.

. Eu não sei cantar: entrevista com Conceição Evaristo. In: Revista Raça, nº 96, mar. . Entrevista. Jornal Estado de Minas. 24 abr. 2007.

. Cadernos Negros 13: poesia. São Paulo: Quilombhoje, 1990.

. Cadernos Negros 19: poesia. São Paulo: Quilombhoje, 1996.

. Cadernos Negros 25: poesia. São Paulo: Quilombhoje, 2002.

FONSECA, Nazareth. Literatura Negra, Literatura Afro-Brasileira: Como responder à Polêmica? In: Literatura Afro-Brasileira. Salvador: Centro de Estudos Afro-Orientais; Brasília: Fundação Cultural Palmares. 2006.

GILROY, Paul. O Atlântico Negro. São Paulo: Editora 34; Rio de Janeiro: Universidade Cândido Mendes, Centro de Estudos Afro-Asiáticos, 2001.

GONZALES, Lélia. Mulher negra. 1994. Disponível em: http://www.leliagonzalez.org.br/ Acesso em: 17 jun. 2007.

HALL, Stuart. Que "negro" é esse na cultura negra? In: Da diáspora: identidades e mediações culturais. Belo Horizonte: Editora UFMG, 2006.

HOOKS, Bell. Alisando o nosso cabelo. 2005. Disponível em: http://www.lppuerj.net/olped/acoesafirmativas/bancoopinioes.asp?pagatual=1\&varpagmax $=10 \&$ numpagmax $=10 \&$ submit $=5 \&$ ordem $=\&$ string busca $=\&$ campo_busca $=-$ Acesso em: 15 jun. 2007.

RUFINO, Alzira. Mulher negra: uma outra história. Disponível em: http://www.casadeculturadamulhernegra.org.br/quem_somos_frameset.htm - Acesso em: 17 jun. 2007.

SAID, Edward. Cultura e imperialismo. São Paulo: Companhia das Letras, 1995.

SANTIAGO. Silviano. Democratização no Brasil - 1979-1981 (Cultura versus Arte). In: ANTELO et alii. Declínio da Arte e Ascensão da Cultura. Florianópolis: ABRALIC/Letras Contemporâneas, 1998. p. 11-23. 
SOUZA, Florentina. Literatura Afro-Brasileira: algumas reflexões. In: Revista Palmares. Ano 1. n. 2. dez. 2005.

RECEBIDO EM: 07 de maio de 2012

APROVADO EM: 13 de junho de 2012 